\title{
Originals
}

\section{Gastric and oesophageal emptying in patients with Type 2 (non-insulin-dependent) diabetes mellitus}

\author{
M. Horowitz ${ }^{1}$, P.E. Harding ${ }^{2}$, A. F. Maddox ${ }^{1}$, J.M. Wishart ${ }^{1}$, L. M. A. Akkermans ${ }^{4}$, B. E. Chatterton ${ }^{3}$ \\ and D.J.C.Shearman ${ }^{1}$ \\ ${ }^{1}$ Department of Medicine, University of Adelaide, ${ }^{2}$ Departments of Endocrinology, and \\ ${ }^{3}$ Nuclear Medicine, Royal Adelaide Hospital, Adelaide, South Australia, and \\ ${ }^{4}$ Department of Experimental Surgery, University Hospital, Utrecht, The Netherlands
}

Summary. Gastric emptying of a digestible solid and liquid meal and oesophageal emptying of a solid bolus were measured with scintigraphic techniques in 20 randomly selected Type 2 (non-insulin-dependent) diabetic patients receiving oral hypoglycaemic therapy and 20 control subjects. In the diabetic patients, the relationships between oesophageal emptying, gastric emptying, gastrointestinal symptoms, autonomic nerve function and glycaemic control were examined. The percentage of the solid meal remaining in the stomach at $100 \mathrm{~min}(p<0.001)$, the $50 \%$ gastric emptying time for the liquid meal $(p<0.05)$ and oesophageal emptying $(p<0.05)$ were slower in the diabetic patients compared to the control subjects. Scores for upper gastrointestinal symptoms and autonomic nerve dysfunction did not correlate significantly $(p>0.05)$ with oesophageal, or gastric emptying. The
$50 \%$ gastric emptying time for the liquid meal was positively related $(r=0.58, p<0.01)$ to the plasma glucose concentration at the time of the performance of the gastric emptying test and the lag period, before any solid food emptied from the stomach, was longer $(p<0.05)$ in subjects with plasma glucose concentrations during the gastric emptying measurement greater than the median, compared to those with glucose concentrations below the median. These results indicate that delayed gastric and oesophageal emptying occur frequently in Type 2 diabetes mellitus and that delayed gastric emptying relates, at least in part, to plasma glucose concentrations.

Key words: Diabetes mellitus, stomach, oesophagus, gastric emptying, oesophageal emptying, autonomic nerve function.
Abnormal gastrointestinal motility is a well recognised complication of diabetes mellitus [1-20]. Gastric and oesophageal motor dysfunction in diabetic patients may result in significant upper gastrointestinal symptoms $[2,4,5,13-15]$, and delayed gastric emptying may contribute to poor blood glucose control [10]. A recent study demonstrated that oesophageal emptying of a solid bolus was delayed in $42 \%$, and gastric emptying of either the solid or the liquid component of a meal was delayed in $56 \%$ of a group of 45 randomly selected Type 1 (insulin-dependent) diabetic patients [2]. No studies have adequately assessed the prevalence of abnormal oesophageal or gastric emptying in Type 2 (non-insulin-dependent) diabetes mellitus, although it has been assumed that disordered gastrointestinal motility occurs less frequently than in Type 1 diabetes mellitus [6]. We have used sensitive scintigraphic techniques to determine the prevalence of abnormal gastric and oesophageal emptying in 20 Type 2 diabetic subjects. The relationships between gastric emptying, oesophageal emptying, gastrointestinal symptoms, autonomic nerve function and glycaemic control have been examined.

\section{Subjects and methods}

The studies were performed in 20 patients ( 9 male, 11 female), mean age 60 years (range 42-77), mean body mass index (BMI) 27.8 (range 24.1-35.9) and mean body weight $75 \mathrm{~kg}$ (range 52-92), who were selected by random number from all the ambulant out-patients who were being treated with oral hypoglycaemic drug(s) (glibenclamide, gliclazide, tolbutamide and/or metformin) for Type 2 diabetes mellitus of at least 12 month's duration by two members (MH \& PH) of the Endocrine Unit of the Royal Adelaide Hospital. Patients were not included in the study if they were taking any medication other than oral hypoglycaemic drugs, or there was a history of upper gastrointestinal surgery or peptic ulcer disease. The mean duration of known diabetes was 8 years (range 1-20), and the majority of the patients had other complications of diabetes mellitus including nephropathy, retinopathy and peripheral neuropathy. Some of the characteristics of the diabetic patients are shown in Table 1. Delayed gastric or oesophageal emptying due to organic obstruction was excluded by upper gastrointestinal endoscopy. Written informed consent was obtained in all cases, and the study was approved by the Ethics Subcommittee of the Royal Adelaide Hospital.

On one day, each diabetic patient underwent: (a) a subjective assessment of gastrointestinal symptoms, (b) an objective assessment of diabetic complications of autonomic neuropathy, peripheral neuropathy and retinopathy, (c) an assessment of glycaemic control, (d) measurement of gastric emptying of a mixed solid and liquid meal, and (e) measurement of oesophageal emptying of a digestible solid 


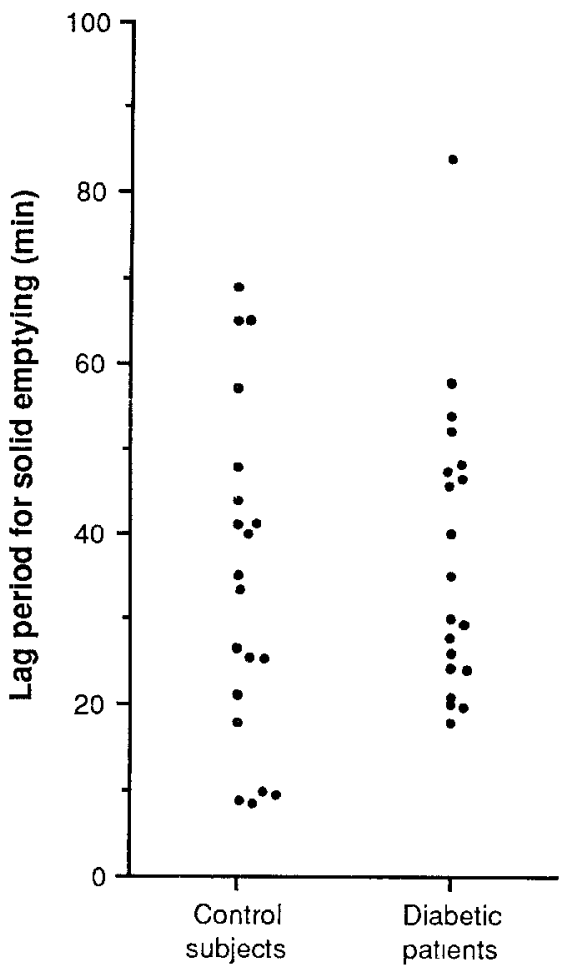

(20)

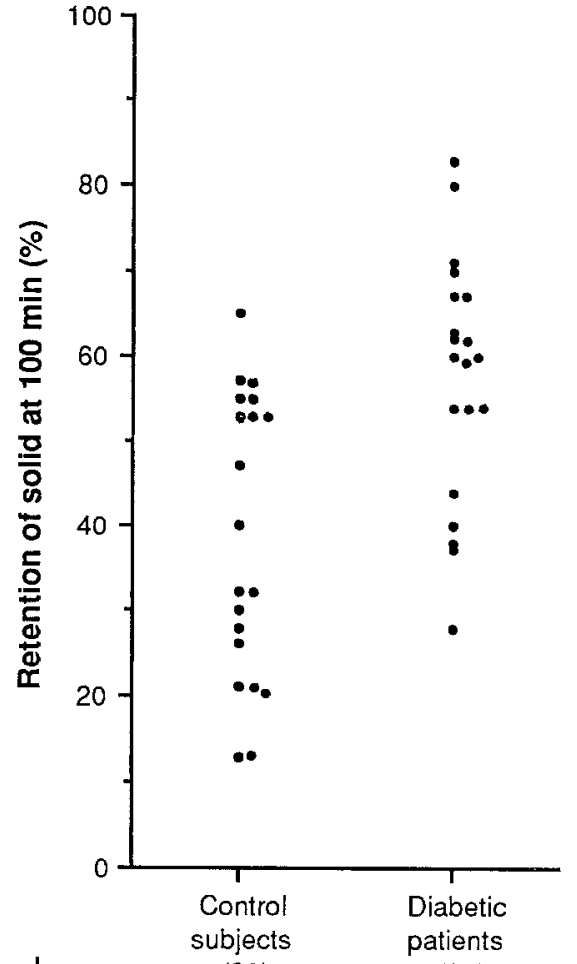

(20)
Fig.1. Individual results for solid gastric emptying expressed as: a the lag period before food left the stomach and $\mathbf{b}$ the percentage of the solid meal remaining at $100 \mathrm{~min}$ in control subjects and in patients with Type 2 (non-insulin-dependent) diabetes mellitus. $(p<0.001)$ bolus. On the study day, smoking was prohibited, and no patient took any medication until after the completion of the tests.

Gastric and oesophageal emptying measurements were also performed in 20 normal volunteers (mean body weight $65 \mathrm{~kg}$, range 47-77) selected to be matched for sex and age (within 5 years) to each diabetic patient. All the control subjects were within $10 \%$ of ideal weight (mean BMI 22.7) (Metropolitan Life Insurance Criteria), nonsmokers, on no medication and with no evidence of gastrointestinal disease. All the diabetic and control subjects were Caucasian.

The diabetic group was significantly heavier $(p<0.01)$ and had a higher BMI $(p<0.01)$ than the control group.

\section{Assessment of gastrointestinal symptoms}

Before the performance of the gastric and oesophageal emptying tests, gastrointestinal symptoms were assessed by a standard questionnaire $[2,4,5]$. Anorexia, nausea, early satiety, upper abdominal discomfort or distention, vomiting, abdominal pain ("gastric" symptoms), dysphagia, heartburn and acid regurgitation ("oesophageal" symptoms) were scored according to the following scheme: $0=$ normal, $1=$ mild (symptom could be ignored if the patient did not think about it), $2=$ moderate (symptom could not be ignored, but did not influence daily activities), $3=$ severe (symptom influenced daily activities). The maximum possible total score for the gastric symptoms was 18 and was 9 for the oesophageal symptoms.

The number of bowel actions each week, the consistency of bowel actions and the presence or absence of nocturnal diarrhoea and faecal incontinence were also noted. The patient was considered to suffer from constipation if less than three spontaneous bowel actions occurred each week $[2,4,5]$.

\section{Assessment of autonomic neuropathy, peripheral neuropathy and retinopathy}

Autonomic neuropathy was assessed by standard cardiovascular reflex tests. Parasympathetic function was evaluated by the heart rate variation ( $R-R$ interval) during deep breathing and the immediate heart rate response to standing (30:15 ratio). Sympathetic function was assessed by the fall in systolic blood pressure in response to standing. The result of each of these three tests was scored as $0=$ normal, $1=$ borderline, 2 =abnormal (for a maximum possible score of 6 ), according to criteria outlined by Ewing and Clarke [21]. A total score of $\geq 3$ was taken to indicate definite autonomic nerve damage $[2,5]$.

Retinopathy was graded as none, background or proliferative on the basis of a recent ophthalmological assessment, which often included fluoroscein angiography.

Peripheral neuropathy was diagnosed clinically when absent ankle reflexes were associated with either sensory or motor changes.

\section{Assessment of glycaemic control}

An indwelling venous cannula was used to obtain $5 \mathrm{ml}$ blood samples 5 min before and at $30,60,90$ and $120 \mathrm{~min}$ after the commencement of each gastric emptying test for measurement of the plasma glucose concentration.

Haemoglobin $\mathrm{A}_{1 \mathrm{c}}\left(\mathrm{HbA}_{1 \mathrm{c}}\right)$ was measured (using the initial venous sample) by a modification of the fast protein liquid chromatographic assay described by Jeppsson et al. [22]. The $\mathrm{HbA}_{1 \mathrm{c}}$ results were expressed as a percentage; the range in normal subjects being $3.5-6.0 \%$.

\section{Measurement of gastric emptying}

Details of this double isotope test, which measures both solid and liquid gastric emptying simultaneously, have previously been published $[2,4,5,23,24]$. The solid meal was $100 \mathrm{~g}$ of cooked ground beef containing $1.0-1.5 \mathrm{mCi}$ of in vivo labelled ${ }^{99 \mathrm{~m}} \mathrm{Tc}$-sulphur colloidchicken liver [23]. The liquid meal was $150 \mathrm{ml}$ of $10 \%$ dextrose in water labelled with $0.75-1 \mathrm{mCi}$ of ${ }^{113 \mathrm{~m}} \mathrm{In}$-DTPA. The test was performed at $\mathbf{1 0 . 0 0}$ hours (after the subject had fasted from solids from 19.00 hours and liquids from 24.00 hours the previous day). The study was performed in the sitting position with the scintillation camera behind the patient. The subject initially ate the solid meal over a $5 \mathrm{~min}$ 


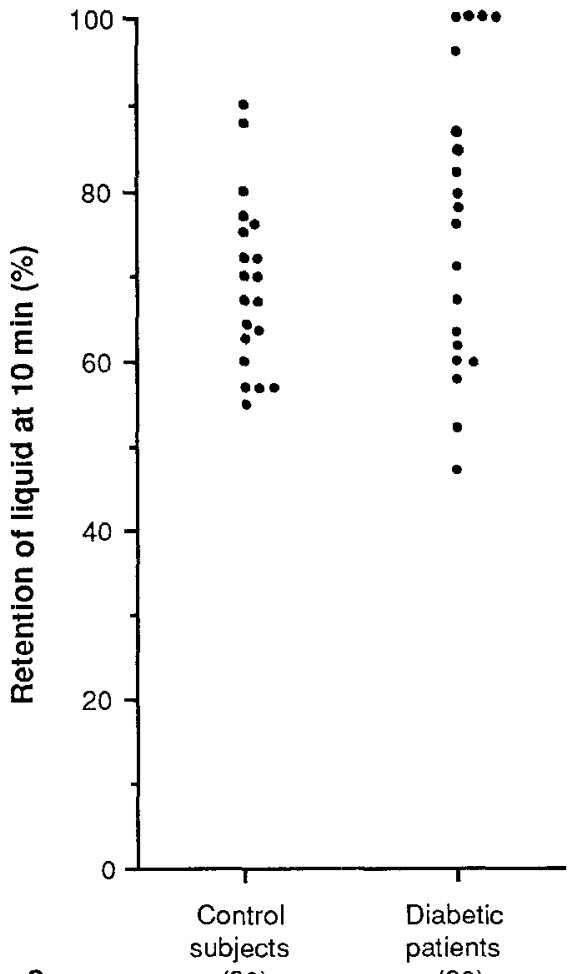

a

(20)

(20)

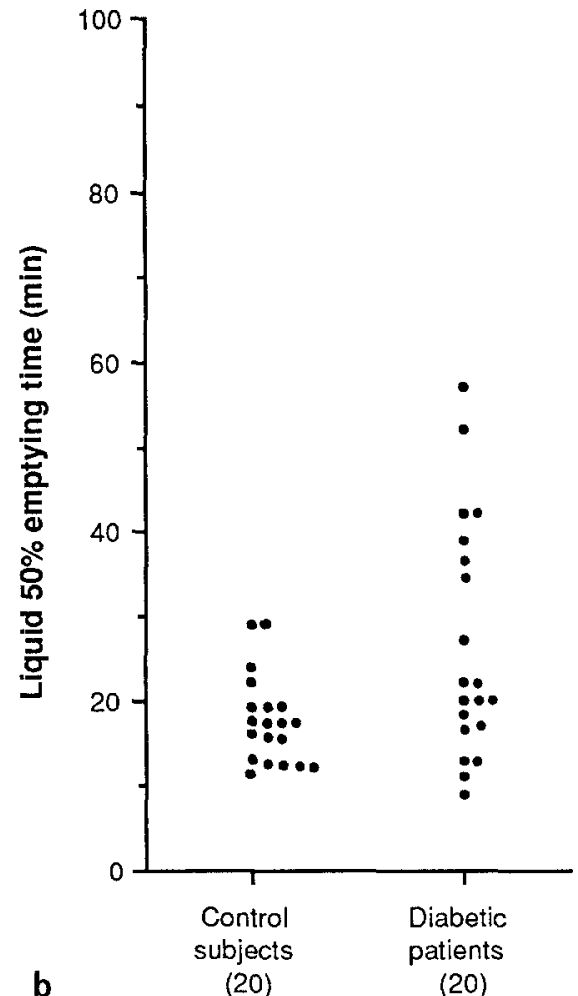

(20)
Fig. 2. Individual results for liquid gastric emptying expressed as: a the percentage of the liquid meal remaining at $10 \mathrm{~min}$ and b the time taken for $50 \%$ of the liquid meal to empty from the stomach in control subjects and in patients with Type 2 diabetes mellitus. $(p<0.05)$ period and then immediately drank the dextrose solution. Time zero was defined as the time of meal completion, and then each study was continued for at least $2 \mathrm{~h}$.

Data was corrected for patient movement, radionuclide decay, Compton scatter and gamma ray (tissue) attenuation using previously described methods $[23,24]$. From the histograms of solid and liquid emptying (expressed as a percentage of the total meal remaining within the stomach vs time), several parameters were derived for subsequent analysis. For the solid component, these parameters were the lag period before food left the stomach and the percentage remaining at $100 \mathrm{~min}$ after meal completion.

The $50 \%$ emptying time for the solid meal was not used because some patients did not reach 50\% emptying in the study period. Similarly, in some patients with markedly delayed emptying the linear emptying rate could not be determined accurately.

For the liquid component, the percentage remaining at $10 \mathrm{~min}$ after meal completion and the time for $50 \%$ emptying (T50) were obtained $[2,4,5]$. The percentage of liquid remaining at $10 \mathrm{~min}$ was used as an index of the early phase of gastric emptying.

\section{Measurement of oesophageal emptying}

This test, which measures the emptying of a solid bolus, has been described previously [2,5]. Before the commencement of the gastric emptying test, after swallowing $5 \mathrm{ml}$ of water as a lubricant, the seated subject swallowed a $10 \mathrm{~g}$ bolus of the solid meal and was then asked to swallow on command every $15 \mathrm{~s}$. Cricoid movement was monitored during the performance of the test to ensure that no additional swallows were taken and the visual display of the gamma camera was used to confirm that the bolus had entered the oesophagus after the first swallow (using the level of the cricoid cartilage). The test was continued until the bolus was seen to enter the stomach, or until 20 swallows $(=300 \mathrm{~s}$ ) had been performed. Analysis was performed by computer-drawn regions of interest corresponding to the oesophagus (cricoid to gastrooesophageal junction) and the stomach. The time for $95 \%$ of the radioactivity to enter the stomach was calculated $[2,5]$.

\section{Statistical analysis}

Data were evaluated using the Mann-Whitney U-test (unpaired data) and linear regression analysis.

\section{Results}

\section{Gastric emptying}

Solid emptying. In the control and the diabetic subjects, solid emptying was slower than liquid emptying and was characterised by an initial lag period, followed by an emptying phase that usually approximated a linear pattern. There was a significant delay of solid food emptying in the diabetic patients. The lag period was not significantly different from the control subjects (although it was grossly prolonged in one diabetic subject) (Fig. 1), but there was increased $(p<0.001)$ retention of solid food at $100 \mathrm{~min}$. The percentage retention of solid food at 100 min was greater than the upper limit of the control range in 6 of the 20 diabetic subjects $(30 \%)$ (Fig. 1).

Liquid emptying. The emptying curve for liquid was non-linear with a slope that decreased with time and usually approximated a monoexponential pattern in both control and diabetic subjects. The T50 for the liquid meal was slower $(p<0.05)$ in the diabetic patients than in the control subjects, but the percentage of the liquid meal remaining at $10 \mathrm{~min}$ was not significantly different between control subjects and diabetic patients. 


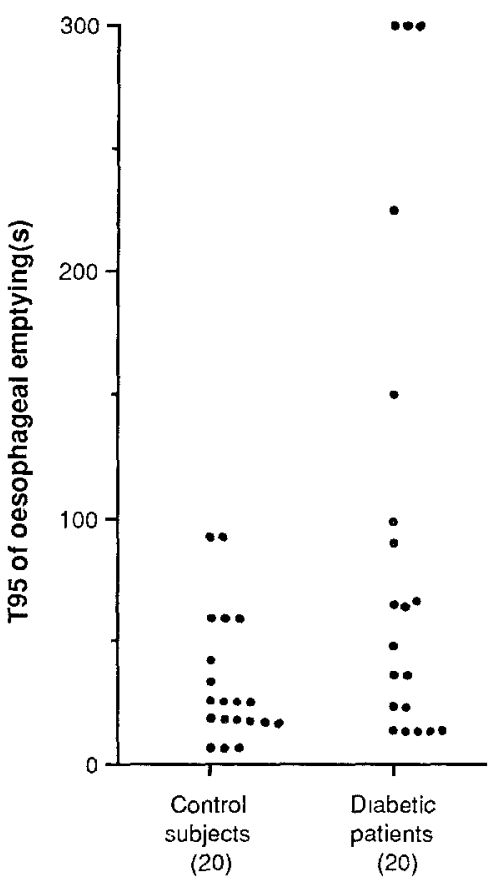

Fig.3. The number of $s$ required to empty the oesophagus of $95 \%$ of the activity of a standard bolus (T95) in control subjects and diabetic patients. The test was ended if 20 swallows $(=300 \mathrm{~s})$ failed to clear the oesophagus. $(p<0.05)$

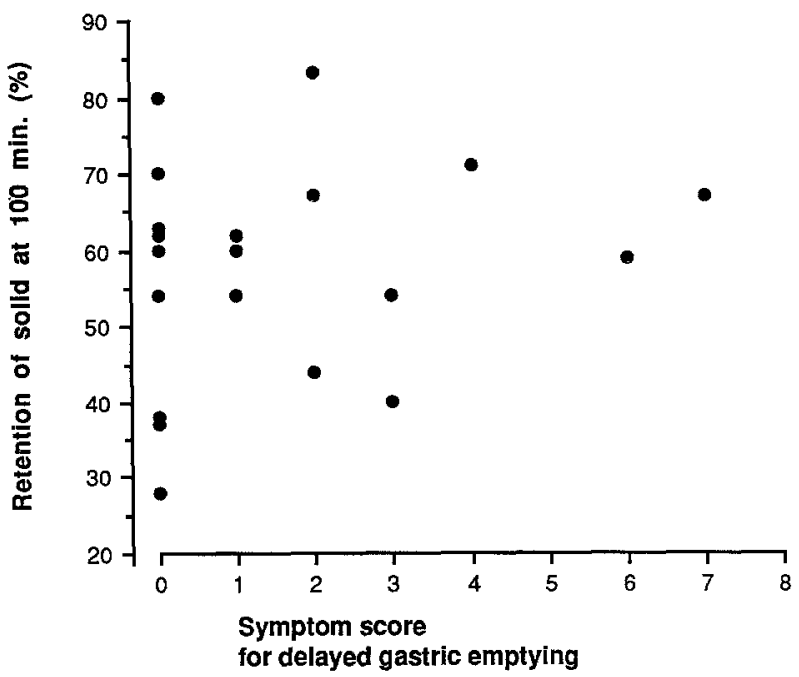

Fig.4. The relationship between the symptom score for delayed gastric emptying and the percentage retention of the solid meal at $100 \min (r=0.19, \mathrm{NS})$

The liquid T50 was greater than the upper limit of the control range in seven patients $(35 \%)$ and less than the lower limit in two patients $(10 \%)$. The percentage retention at 10 min was greater than the upper limit of the control range in five of the diabetic patients $(25 \%)$ and less than the lower limit in two patients (10\%) (Fig. 2).

Relationship between solid and liquid emptying in diabetic patients. There were significant correlations between the percentage retention of the liquid meal at $10 \mathrm{~min}$ and both the solid lag period $(r=0.43, p<0.05)$ and the percentage retention of the solid meal at $100 \min (r=0.49, p<0.05)$. The correlations between the liquid T50 and both the solid lag period $(r=0.35$, NS) and the percentage retention of the solid meal at $100 \min (r=0.34$, NS) were not statistically significant.
Of the 20 diabetic patients, 10 had delayed gastric emptying (values greater than the upper limit of the control range) for solid gastric emptying (percentage retention at $100 \mathrm{~min}$ ), liquid gastric emptying (T50), or both.

\section{Oesophageal emptying}

In all subjects, the bolus of food entered the oesophagus after the first swallow, and no food was retained in the oesophagus after the consumption of the liquid meal. The diabetic group had significantly delayed $(p<0.05)$ oesophageal emptying; and in six of the 20 patients $(30 \%)$, the time for $95 \%$ oesophageal emptying of the solid bolus was greater than the upper limit of the control range (Fig.3). Visual inspection of the computer images demonstrated that in the diabetic patients with delayed oesophageal emptying, retardation of the bolus occurred in both the middle and distal parts of the oesophagus. There was no significant correlation between oesophageal emptying and either liquid or solid gastric emptying.

\section{Gastrointestinal symptoms}

There was considerable variation in gastrointestinal symptoms between patients (Table 1). Five of the 20 patients $(25 \%)$ had a score for gastric symptoms of 3 or more out of a possible 18, and nine patients had no symptoms (Fig.4). Oesophageal symptoms were also extremely variable, with a median score of 0.5 (range 0-8). Two patients suffered from dysphagia, and seven suffered acid regurgitation. Of the other gastrointestinal symtpoms, one patient suffered from constipation; none had nocturnal diarrhoea; and two suffered faecal incontinence.

\section{Diabetic complications}

The autonomic neuropathy scores are shown in Figure 5 and Table 1. Eight patients had definite evidence of autonomic neuropathy (total score $\geq 3$ ), and 16 $(80 \%)$ had a score of 1 or more. The score for autonomic nerve dysfunction correlated significantly $(r=0.45$, $p<0.05$ ) with the age of the subject, but not with the duration of diabetes mellitus. Six patients clinically had peripheral neuropathy. Fifteen patients had no retinopathy, four patients had background retinopathy; and one patient had proliferative retinopathy.

\section{Glycaemic control}

Plasma glucose and $\mathrm{HbA}_{1 \mathrm{c}}$ concentrations varied considerably between patients (Fig. 6, Table 1). On the basis of the $\mathrm{HbA}_{1 \mathrm{c}}$ results, no patient was in the range for nor- 
Table 1. See text

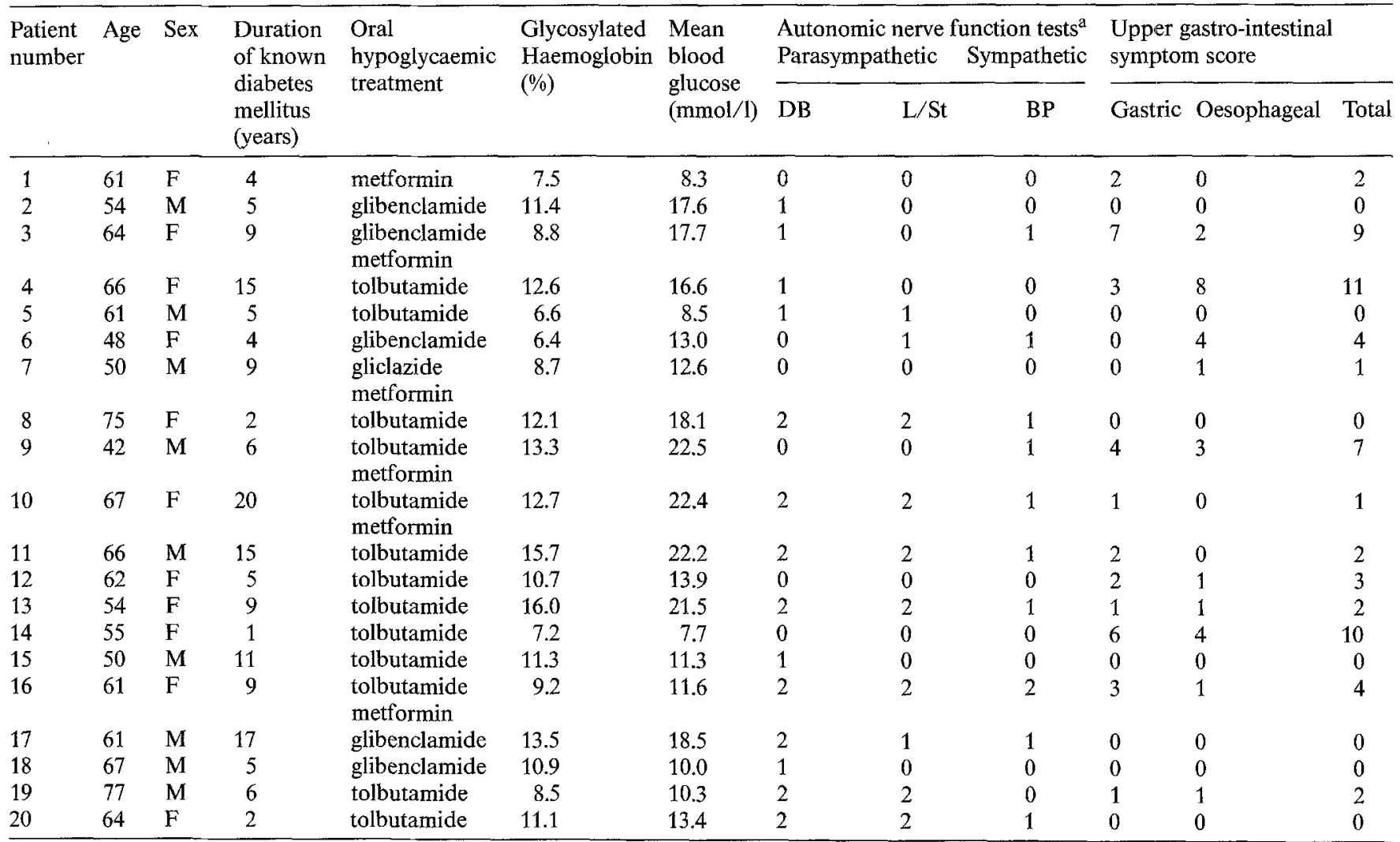

a $0=$ normal; $1=$ borderline; $2=$ abnormal $\mathrm{DB}=$ heart rate response to deep breathing; $\mathrm{L} / \mathrm{St}=$ lying/standing heart rate; $\mathrm{BP}=\mathrm{systolic}$ blood pressure response to standing

mal; seven patients were in the range 6.1-9.0\%, six patients were in the range $9.1-12.0 \%$; and seven patients had values $>12.0 \%$. The plasma glucose concentrations (at $-5,30,60,90$ and 120 min and the mean) were each directly related to the $\mathrm{HbA}_{1 \mathrm{c}}$ concentration $(r>0.75$, $p<0.001)$ and all of the plasma glucose measurements taken during the gastric emptying test were directly related to each other $(r>0.91, p<0.001)$.

The duration of known diabetes mellitus (but not age) correlated significantly with both $\mathrm{HbA}_{1 \mathrm{c}}(r=0.54$, $p<0.05)$ and mean plasma glucose $(r=0.55, p<0.01)$. There were weak $(r=0.43, p<0.05$ for both) but significant correlations between $\mathrm{HbA}_{1 \mathrm{c}}$ and the mean plasma glucose and the score for autonomic nerve dysfunction.

\section{Relationships between oesophageal and gastric emptying and other parameters in diabetic subjects}

Age, sex and duration of diabetes mellitus. Oesophageal, gastric liquid and gastric solid emptying were not significantly related to age or the duration of known diabetes mellitus. No effect attributable to sex was seen for any of the parameters.

Gastrointestinal symptoms. There was no significant correlation between oesophageal, gastric or the total score for upper gastrointestinal symptoms and any pa-

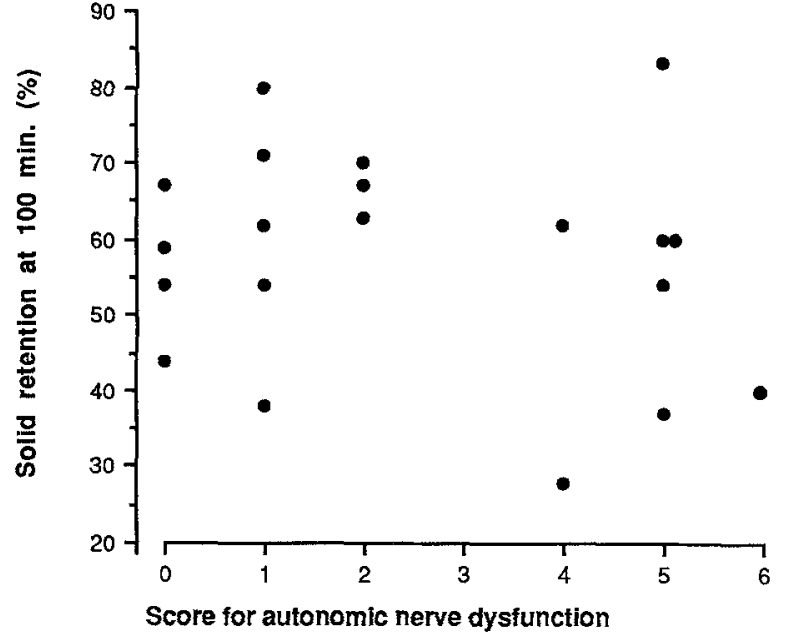

Fig.5. The relationship between the percentage retention of the solid meal at $100 \mathrm{~min}$ and the score for autonomic nerve dysfunction in diabetic patients $(r=0.19, \mathrm{NS})$

rameter of oesophageal or gastric emptying. Although there was a trend for patients with the higher gastric scores to have delayed gastric emptying, a number of patients with no or minimal upper gastrointestinal symptoms had delayed gastric emptying (Fig. 4).

Autonomic neuropathy. There was no significant correlation between the total score for autonomic nerve dysfunction, or the total score for parasympathetic nerve 


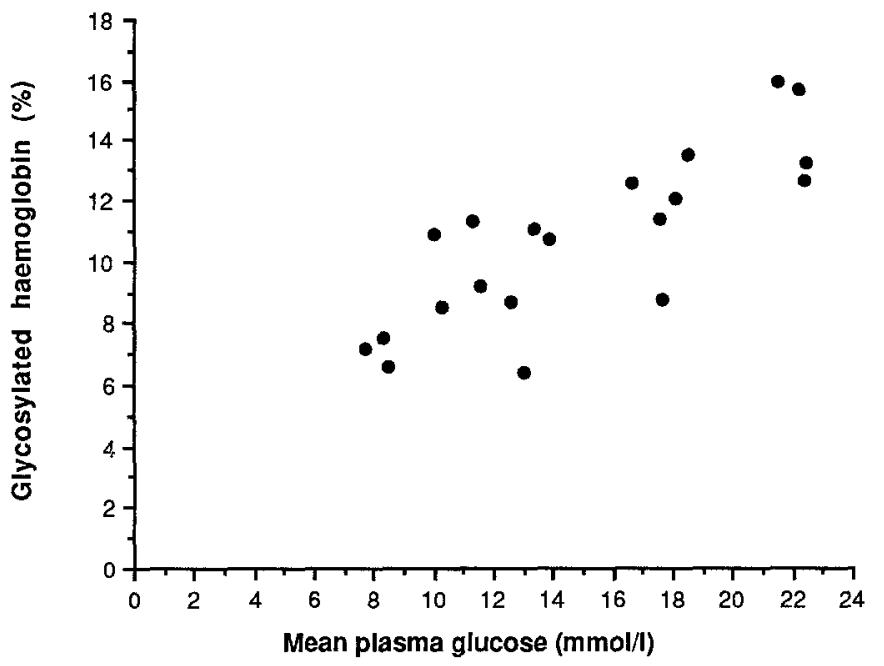

Fig. 6. The relationship between glycosylated haemoglobin $\left(\mathrm{HbA}_{1 \mathrm{c}}\right)$ and the mean plasma glucose concentration during the first 120 min of the gastric emptying test in diabetic patients $(r=0.82, p<0.01)$

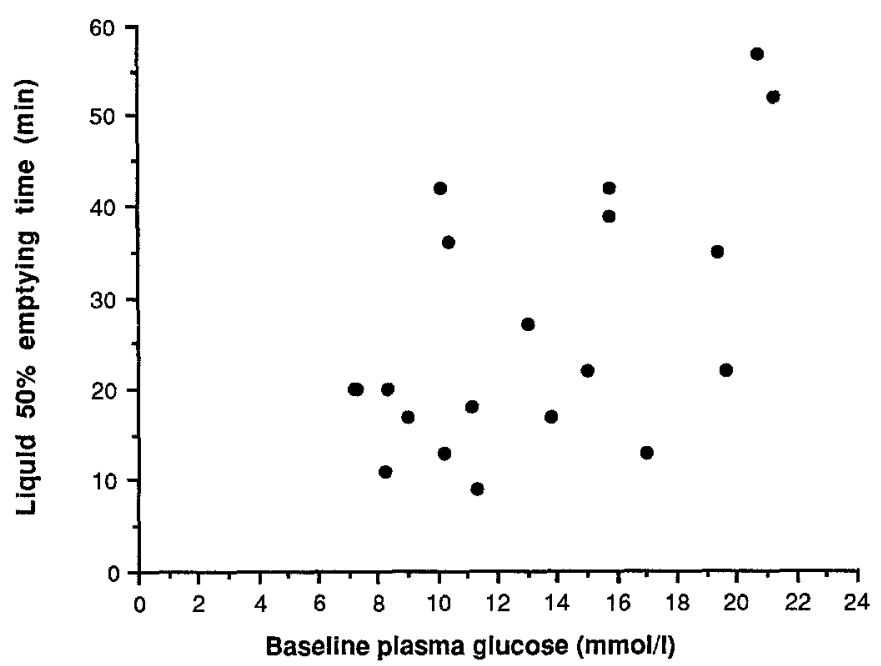

Fig. 7 The relationship between the $50 \%$ emptying time for the liquid meal and the plasma glucose concentration $5 \mathrm{~min}$ before the commencement of the gastric emptying measurement in diabetic patients $(r=0.58, p<0.01)$

dysfunction and any parameter of oesophageal or gastric emptying (Fig. 5).

Glycaemic control. There was no significant correlation between either plasma glucose or $\mathrm{Hb}_{1 \mathrm{c}}$ concentrations and oesophageal or gastric solid emptying. The T50 for gastric emptying of the liquid meal correlated significantly with plasma glucose concentrations at $-5,30$, 60,90 and $120 \mathrm{~min}$ and the mean plasma glucose $(r>0.50, p<0.05)$ (Fig. 7) but not with $\mathrm{HbA}_{1 \mathrm{c}}(r=0.19$, NS). There was no significant correlation between solid gastric emptying and either plasma glucose concentrations or $\mathrm{HbA}_{1 \mathrm{c}}$. For the solid lag period, the correlation with mean plasma glucose was $r=0.37$ and with $\mathrm{HbA}_{1 \mathrm{c}}$ $r=0.15$. The solid lag period was, however, significantly $(p<0.05)$ longer in diabetic patients with mean plasma glucose concentrations greater than the median level during the gastric emptying study (median T50 of
$48 \mathrm{~min}$ ) compared to those with plasma glucose concentrations below the median (median T50 of $30 \mathrm{~min}$ ). There was no significant difference in the liquid T50 when the patients were divided similarly according to $\mathrm{HbA}_{1 \mathrm{c}}$ concentrations.

\section{Discussion}

\section{Gastric emptying}

This study is the first comprehensive evaluation of gastric emptying in patients with Type 2 diabetes mellitus, and the findings indicate that in this particular subgroup of Type 2 patients there is a high prevalence of gastric motor dysfunction, comparable to that demonstrated in patients with Type 1 diabetes mellitus $[2,15]$. The majority of the patients had long standing diabetes mellitus, with variable glycaemic control, and there was a high prevalence of the complications autonomic neuropathy, peripheral neuropathy and retinopathy, but this population cannot be considered to be unusual. Our observations cannot be ascribed to the effect of aging on gastric emptying [25], and the slight but significant difference in body weight between the control and the diabetic groups is unlikely to be of importance [26]. There is no information to suggest that oral hypoglycaemic drugs may directly influence gastrointestinal motility, and such studies would be difficult to perform in normal subjects. In addition, as the last dose of oral hypoglycaemic drug(s) was given at least $15 \mathrm{~h}$ before the gastric and oesophageal emptying measurements, plasma drug concentrations would have been low. An effect of oral hypoglycaemic drugs on our findings, therefore, cannot be excluded but is unlikely. On the basis of previous results in patients with Type 1 diabetes mellitus, we would predict that the majority of Type 2 diabetic patients with slow gastric emptying of radioisotopically labelled meals would have a normal result with liquid barium sulphate $[9,20]$.

The normal stomach empties liquid, digestible solid and non-digestible solid meal components at different rates and with different patterns, but the motor mechanisms controlling this are poorly defined [27-29]. The gastro-duodenal pressure gradient, which is influenced by proximal gastric tone and pyloric and duodenal resistance, is of major importance in the control of liquid emptying [27, 29]. By contrast the grinding action of the antrum has a major influence in controlling gastric emptying of digestible solid food [27]. Our observations suggest that proximal stomach and antral motor activity is frequently diminished in patients with Type 2 diabetes mellitus, consistent with manometric [11-14] and scintigraphic $[2,4,5,8,9,15,16]$ studies in Type 1 diabetic patients. Disordered pyloric motility may also contribute to delayed emptying [14].

The finding that gastric emptying is frequently delayed in patients with Type 2 diabetes mellitus is per- 
haps not surprising [30]. Gastric bezoar has been reported in these patients [31] and abnormalities of gastric emptying have been demonstrated in two studies, which have measured gastric emptying in small numbers of selected patients with Type 2 diabetes mellitus $[32,33]$. Leatherdale et al. [32] studied gastric emptying of a porridge meal in 10 patients with longstanding Type 2 diabetes mellitus and in 10 control subjects. The results of this study may be questioned because of probable technical inaccuracies [23, 24], but the time for $50 \%$ of the "peak content" of the meal to empty from the stomach was longer in the diabetic patients. Sasaki et al. [33] reported that gastric emptying of a water load was slower in a small group of obese Pima Indians with Type 2 diabetes mellitus compared to obese control subjects. In two of our 20 diabetic patients, gastric emptying of the liquid meal was faster than any control subject. This more rapid initial emptying has been demonstrated in Type 1 diabetes mellitus patients $[2,9,15]$ and may reflect impaired proximal stomach accomodation to distension [34], or abnormal pyloric motility [14, 29]. The emptying of larger non-digestible solid particles, which is dependent on the integrity of phase 3 of the gastric interdigestive myoelectric complex, was not assessed in our study, but in symptomatic Type 1 diabetic patients gastric interdigestive myoelectric complexes are characteristically absent [11-13], and gastric emptying of non-digestible solid particles is markedly delayed [35].

This study demonstrates that the poor correlation between gastrointestinal symptoms and gastric emptying in Type 1 diabetic patients $[2,15]$ also exists in Type 2 diabetes mellitus patients. Although some patients with gastrointestinal symptoms had delayed gastric emptying, it also occurred in asymptomatic patients. The relatively high prevalence of gastrointestinal symptoms is not unexpected $[1,2,15]$, and it is probable that gastrointestinal complications represent a generally underestimated cause of morbidity in both forms of diabetes mellitus.

A high prevalence of autonomic nerve dysfunction in Type 2 diabetes mellitus patients has been reported $[36,37]$, and it is well documented that abnormal autonomic nerve function tests precede the development of symptomatic autonomic neuropathy [36]. The absence in this study of a significant relationship between gastric emptying and the severity of autonomic nerve dysfunction differs from findings in Type 1 diabetes mellitus patients $[2,8,15]$ and has several possible explanations. Only 4 of the 20 patients had no evidence of autonomic neuropathy, and it is possible that minimal abnormalities in cardiac autonomic nerve function are associated with disordered gastric motility. In addition, the relative impairments in sympathetic vs parasympathetic gastric innervation are likely to influence gastric emptying [13]. It is also possible that in the diabetic autonomic neuropathy syndrome gastric and cardiac systems may be affected differently [38], and that vagal gastric damage may not necessarily by inferred from cardiac vagal dysfunction, but this hypothesis conflicts with the demonstration of a strong association between gastric acid output impairment and cardiac autonomic neuropathy [39].

The observation that the liquid T50 and the solid lag period are related to plasma glucose concentrations in Type 2 diabetic patients is consistent with our observations in Type 1 diabetes mellitus patients [2], although not with those made by other workers [16]. Induced hyperglycaemia in normal subjects slows gastric emptying of nutrient-containing liquid meals $[40,41]$ and decreases fasting antral contractility and gastric phase 3 activity [42]. The poor reproducibility of gastric emptying that has been observed in Type 2 diabetic patients [32], and the variable observations on liquid gastric emptying in Type 1 diabetic patients $[2,9,15,16,20]$ may possibly be partly ascribed to variations in plasma glucose concentrations. The mechanism(s) responsible for the inhibitory action of hyperglycaemia on gastric motility is not known. Hyperglycaemia may suppress vagal nerve activity [43] and be an important factor in the aetiology of autonomic nerve dysfunction [44]. Alterations in gastrointestinal hormone secretion (such as motilin, pancreatic polypeptide, somatostatin, glucagon, gastrin and gastric inhibitory polypeptide) may be important [30]. Although plasma glucose and glycosylated haemoglobin concentrations correlated closely in our study, there was no significant relationship between gastric emptying and glycosylated haemoglobin. This latter observation suggests, but certainly does not prove, that delay in gastric emptying is more closely linked to acute, rather than chronic hyperglycaemia.

\section{Oesophageal emptying}

Recent studies suggest that tests measuring oesophageal radionuclide transit using liquid or solid boluses are as sensitive as manometric techniques in detecting oesophageal motor dysfunction, particularly in those disorders characterised by disorganised contractions $[45,46]$. Our results indicate that there is a high prevalence of oesophageal motor dysfunction in patients with Type 2 diabetes mellitus; the time for $95 \%$ of a solid bolus to empty from the oesophagus was greater than the control range in six of the 20 diabetic patients. Delayed transit correlated poorly with symptoms of oesophageal dysfunction. These results are consistent with previous radiologic, radio-isotopic and manometric studies $[2,3,7,10,47]$ in Type 1 diabetes mellitus patients. The manometric abnormalities which have been reported in Type 1 diabetic patients include a reduction in the primary peristaltic wave, frequent spontaneous contractions, reduced lower oesophageal sphincter pressure and multiphasic, multipeaked peristaltic pressure wave complexes [3, 47]. Although we were unable to demonstrate a significant correlation, 
delayed oesophageal emptying in Type 2 diabetic patients is likely to reflect autonomic nerve impairment [2, 7]. It should, however, be noted that a correlation between oesophageal motility abnormalities and neuropsychiatric status in diabetic patients has been reported [48].

\section{Relationship of observations to glycaemic control}

In patients with Type 1 diabetes mellitus, alterations in gastric emptying are likely to adversely affect glycaemic control [19]. If the same applies to Type 2 diabetes mellitus, and this has yet to be shown, our results suggest that diabetic gastroparesis may also be an underemphasised contributor to poor glycaemic control in those patients with Type 2 diabetes mellitus. Furthermore, hyperglycaemia may itself lead to delayed gastric emptying and also gastrointestinal symptoms. Type 2 diabetic patients with unexplained poor glycaemic control should possibly be screened for gastric emptying abnormalities and gastrokinetic drugs may have a role in such patients by reducing variations in gastric emptying [5]. Our results provide a further rationale to improve and avoid major fluctuations in plasma glucose levels in Type 2 diabetic patients. While delayed oesophageal emptying in diabetic patients is usually relatively asymptomatic, these patients are at risk for delayed oesophageal transit of capsules and tablets (such as oral hypoglycaemic drugs) with the consequent risks of localised mucosal ulceration and delayed drug absorption [49].

Acknowledgements. This work was supported grants from the National Health and Medical Research Council of Australia and the Rebecca L.Cooper Medical Research Foundation. We wish to thank Mrs. M. Marucci for typing this manuscript.

\section{References}

1. Feldman M, Schiller LR (1983) Disorders of gastrointestinal motility associated with diabetes mellitus. Ann Intern Med 98: 378-384

2. Horowitz M, Harding PE, Maddox A, Maddern GJ, Collins PJ, Chatterton BE, Wishart J, Shearman DJC (1986) Gastric and oesophageal emptying in insulin-dependent diabetes mellitus. J Gastroenterol Hepatol 1: 97-113

3. Hollis JB, Castell DO, Braddom RL (1977) Esophageal function in diabetes mellitus and its relation to peripheral neuropathy. Gastroenterology 73: 1098-1102

4. Horowitz M, Harding PE, Chatterton BE, Collins PJ, Shearman DJC (1985) Acute and chronic effects of domperidone on gastric emptying in diabetic autonomic neuropathy. Dig Dis Sci 30:1-9

5. Horowitz M, Maddox A, Harding PE, Maddern GJ, Chatterton BE, Wishart J, Shearman DJC (1987) Effect of cisapride on gastric and esophageal emptying in insulin-dependent diabetes mellitus. Gastroenterology 92: 1899-1907

6. Kassander P (1958) Asymptomatic gastric retention in diabetics (gastroparesis diabeticorum). Ann Int Med 48: 797-812

7. Channer KS, Jackson PC, O'Brien I, Corrall RJM, Coles DR, Rhys Davies E, Virjee JP (1985) Oesophageal function in diabetes mellitus and its association with autonomic neuropathy. Diabetic Med 2: 378-382
8. Buysschaert M, Moulart M, Urbain JL, Pauwels S, De Roy L, Ketelslegers JM, Lambert AE (1987) Impaired gastric emptying in diabetic patients with cardiac autonomic neuropathy. Diabetes Care 10: $448-452$

9. Campbell IW, Heading RC, Tothill P, Buist, TAS, Ewing DJ, Clarke BF (1977) Gastric emptying in diabetic autonomic neuropathy. Gut 18: 462-467

10. Russell COH, Gannan R, Coatsworth J, Neilsen R, Allen F, Hill LD, Pope CE (1983) Relationship among esophageal dysfunction, diabetic gastroenteropathy and peripheral neuropathy. Dig Dis Sci 28: 289-293

11. Fox S, Behar J (1980) Pathogenesis of diabetic gastroparesis - a pharmacologic study. Gastroenterology 78: 757-763

12. Malagelada J-R, Rees WDW, Mazzotta LJ, Go VLW (1980) Gastric motor abnormalities in diabetic and postvagotomy gastroparesis; effect of metoclopramide and bethanechol. Gastroenterology 78: 286-293

13. Camilleri M, Malagelada J-R (1984) Abnormal intestinal motility in diabetics with the gastroparesis syndrome. Eur J Clin Invest 14: $420-427$

14. Mearin F, Camilleri M, Malagelada J-R (1986) Pyloric dysfunction in diabetics with recurrent nausea and vomiting. Gastroenterology 90: 1919-1925

15. Keshavarzian A, Iber FL, Vaeth J (1987) Gastric emptying in patients with insulin-requiring diabetes mellitus. Am J Gastroenterol 82: 29-35

16. Wright RA, Clemente R, Wathen R (1985) Diabetic gastroparesis: an abnormality of gastric emptying of solids. Am J Med Sci 289: 240-242

17. Achem-Karam SR, Funakoshi A, Vinik AI, Owyang C (1985) Plasma motilin concentration and interdigestive migrating motor complex in diabetic gastroparesis: effect of metoclopramide. Gastroenterology 88: 492-499

18. Smith B (1974) Neuropathology of the esophagus in diabetes mellitus. J Neurol Neurosurg Psychiatry 37:1155-1161

19. Wooten RL, Meriwether TW (1961) Diabetic gastric atony: a clinical study. JAMA 176: 1082-1087

20. Loo FD, Palmer DW, Soergel KH, Kalbfleisch JH, Wood CM (1984) Gastric emptying in patients with diabetes mellitus. Gastroenterology 86: 485-494

21. Ewing DJ, Clarke BF (1982) Diagnosis and management of diabetic autonomic neuropathy. Br Med J 285: 916-918

22. Jeppsson J, Jerntorp P, Sundkvist G, Englund H, Nylund V (1986) Measurement of hemoglobin $\mathrm{A}_{1 \mathrm{c}}$ by a new liquid-chromatographic assay: Methodology, clinical utility, and relation to glucose tolerance evaluated. Clin Chem 32: 1867-1872

23. Collins PI, Horowitz M, Cook DJ, Harding PE, Shearman DJC (1983) Gastric emptying in normal subjects - a reproducible technique using a single scintillation camera and computer system. Gut 24: $1117-1125$

24. Collins PJ, Horowitz M, Shearman DJC, Chatterton BE (1984) Correction for tissue attenuation in radionuclide gastric emptying studies: a comparison of a lateral image method and a geometric mean method. Br J Radiol 57: 689-695

25. Horowitz M, Maddern GJ, Chatterton BE, Collins PJ, Harding PE, Shearman DJC (1984) Changes in gastric emptying rates with age. Clin Sci 67: 213-218

26. Horowitz M, Collins PJ, Cook DJ, Harding PE, Shearman DJC (1983) Abnormalities of gastric emptying in obese patients. Int J Obes 7: 415-421

27. Kelly KA (1980) Gastric emptying of liquids and solids: roles of proximal and distal stomach. Am J Physiol 239: G71-76

28. Camilleri M, Malagelada JR, Brown ML, Becker G, Zinsmeister AR (1985) Relation between antral motility and gastric emptying of solids and liquids in humans. Am J Physiol 12: G580-585

29. Houghton LA, Read NW, Heddle R, Horowitz M, Collins PJ, Chatterton $B_{2}$, Dent $\mathbf{J}(1988)$ The relationship of the motor activity of the antrum, pylorus and duodenum to gastric emptying of a solid-liquid mixed meal. Gastroenterology 94: 1285-1291

30. Ewing J, Clarke BF (1986) Diabetic autonomic neuropathy present insights and future prospects. Diabetes Care 6:648-665 
31. Ahn Y-H, Maturu P, Steinheber FU, Goldman JM (1987) Association of diabetes mellitus with gastric bezoar formation. Arch Int Med 147:527-528

32. Leatherdale BA, Green DJ, Harding LK, Griffin D, Bailey CJ (1982) Guar and gastric emptying in noninsulin dependent diabetes. Acta Diabet Lat 19: 339-343

33. Sasaki H, Nagulesparan M, Dubois A, Straus E, Samloff IM, Lawrence WH, Johnson GC, Sievers ML, Unger RH (1983) Hypergastrinemia in obese noninsulin-dependent diabetes: a possible reflection of high prevalence of vagal dysfunction. J Clin Endocrinol Metab 56: 744-750

34. Oliveira RB, Troncon LEA, Meneghelli UG, Dantas RO, Godoy RA (1984) Gastric accomodation to distension and early gastric emptying in diabetics with neuropathy. Braz J Med Biol Res 17: 49-55

35. Feldman M, Smith HJ, Simon TR (1984) Gastric emptying of solid radiopaque markers: studies in healthy subjects and diabetic patients. Gastroenterology 87: 895-902

36. Sundkvist G, Lilja B (1985) Autonomic neuropathy in diabetes mellitus: a follow-up study. Diabetes Care 1985; 8: 129-133

37. Masaoka S, Lev-Ran A, Hill R, Vaki G, Hon EHG (1985) Heart rate variability in diabetes: relationship to age and duration of the disease. Diabetes Care 8: 64-68

38. Soler NG (1980) Diabetic gastroparesis without autonomic neuropathy. (letter). Diabetes Care 3: 200-201

39. Buysschaert M, Donckier J, Dive A, Ketelslegers J-M, Lambert $\mathrm{AE}$ (1985) Gastric and pancreatic polypeptide responses to sham feeding are impaired in diabetic subjects with autonomic neuropathy. Diabetes 34: 1181-1185

40. MacGregor IL, Gueller R, Watts HD, Meyer JH (1976) The effect of acute hyperglycaemia on gastric emptying in man. Gastroenterology 70: 190-196

41. Aylett P (1962) Gastric emptying and change of blood glucose level as affected by glucagon and insulin. Clin Sci 22: 171-178

42. Barnett JL, Owyang C (1988) Serum glucose concentration as a modulator of interdigestive gastric motility. Gastroenterology 94: 739-744

43. Hirano T, Niijima A (1980) Effects of 2-deoxy-d-glucose, glucose and insulin on efferent activity in gastric vagus nerve. Experienta 36: 1197-1198

44. Pfeifer MA, Weinberg CR, Cook DL, Reenan A, Halter JB, Ensinck JW, Porte D (1984) Autonomic neural function in recently diagnosed diabetic subjects. Diabetes Care 7:447-453

45. Kjellen G, Svedberg JB, Tibbling L (1984) Solid bolus transit by esophageal scintigraphy in patients with dysphagia and normal manometry and radiography. Dig Dis Sci 29:1-5

46. Klein HA, Wald A (1984) Computer analysis of radionuclide esophageal transit studies. J Nucl Med 25: 957-964

47. Loo FD, Dodds WJ, Soergel KH, Arndorfer RC, Helm JF, Hogan WJ (1985) Multipeaked esophageal peristaltic pressure waves in patients with diabetic neuropathy. Gastroenterology 88: 485-491

48. Clouse RE, Lustman PJ, Reidel WL (1986) Correlation of esophageal motility abnormalities with neuropsychiatric status in diabetics. Gastroenterology 90: 146-1154

49. Channer KS, Roberts CJC (1985) The effect of delayed oesophageal transit on the absorption of acetaminophen. Clin Pharmacol Ther 37: 72-76

Received: 19 July 1988

and in revised form: 24 December 1988

Dr. M. Horowitz

Department of Medicine

Royal Adelaide Hospital

North Terrace

Adelaide

South Australia

Australia 5000 